\title{
Microenvironmental adaptation of experimental tumours to chronic vs acute hypoxia
}

\author{
O Thews*,', T Wolloscheck ${ }^{2}$, W Dillenburg', S Kraus', DK Kelleher', MA Konerding ${ }^{2}$ and P Vaupel' \\ 'Institute of Physiology and Pathophysiology, University of Mainz, Duesbergweg 6, 55099 Mainz, Germany; ${ }^{2}$ Institute of Anatomy, University of Mainz, \\ Becherweg 13, 55099 Mainz, Germany
}

This study investigated long-term microenvironmental responses (oxygenation, perfusion, metabolic status, proliferation, vascular endothelial growth factor (VEGF) expression and vascularisation) to chronic hypoxia in experimental tumours. Experiments were performed using s.c.-implanted DS-sarcomas in rats. In order to induce more pronounced tumour hypoxia, one group of animals was housed in a hypoxic atmosphere $\left(8 \% \mathrm{O}_{2}\right)$ for the whole period of tumour growth (chronic hypoxia). A second group was acutely exposed to inspiratory hypoxia for only 20 min prior to the measurements (acute hypoxia), whereas animals housed under normal atmospheric conditions served as controls. Acute hypoxia reduced the median oxygen partial pressure $\left(p \mathrm{O}_{2}\right)$ dramatically $(\mathrm{I}$ vs $10 \mathrm{mmHg}$ in controls), whereas in chronically hypoxic tumours the $\mathrm{pO}_{2}$ was significantly improved (median $p \mathrm{O}_{2}=4 \mathrm{mmHg}$ ), however not reaching the control level. These findings reflect the changes in tumour perfusion where acutely hypoxic tumours show a dramatic reduction of perfused tumour vessels (maybe the result of a simultaneous reduction in arterial blood pressure). In animals under chronic inspiratory hypoxia, the number of perfused vessels increased (compared to acute hypoxia), although the perfusion pattern found in control tumours was not reached. In the chronically hypoxic animals, tumour cell proliferation and tumour growth were significantly reduced, whereas no differences in VEGF expression and vascular density between these groups were observed. These results suggest that long-term adaptation of tumours to chronic hypoxia in vivo, while not affecting vascularity, does influence the functional status of the microvessels in favour of a more homogeneous perfusion.

British Journal of Cancer (2004) 91, I I8I-1 I89. doi: I0.1038/sj.bjc.6602066 www.bjcancer.com

Published online 10 August 2004

(c) 2004 Cancer Research UK

Keywords: hypoxia; oxygenation; vascularity; perfusion; VEGF; cell proliferation

Oxygen deficiency (hypoxia) can be found in many human malignancies (Vaupel et al, 1989; Höckel and Vaupel, 2001) and has been blamed for limiting the efficacy of several nonsurgical tumour treatments such as sparsely ionising radiation (Gray et al, 1953; Bush et al, 1978; Horsman, 1993), $\mathrm{O}_{2}$-dependent chemotherapeutic agents (Teicher et al, 1990; Thews et al, 2001) or photodynamic therapy (Henderson and Fingar, 1987). However, an increasing number of studies clearly demonstrate that tumour hypoxia also has an impact on gene expression, with changes in glycolytic enzymes, growth factors or angiogenic molecules (for a recent review, see Höckel and Vaupel, 2001). Many of these genes are under the control of the hypoxia-inducible factor 1 (HIF-1), which has been found to be accumulated in many tumours (Semenza, 2000, 2002). Most of these processes of gene induction are not tumour specific and also take place in the normal tissue during hypoxia. However, some of them (e.g. hypoxia-induced neovascularisation) may contribute to malignant progression and metastasis (Dachs and Tozer, 2000). In particular, the formation of new blood vessels in growing tumours, which is stimulated by hypoxia-induced upregulation of the vascular endothelial growth factor (VEGF) (Sutherland et al, 1996), seems to play an important

*Correspondence: Dr O Thews; E-mail: OLTHEWS@uni-mainz.de Received II December 2003; revised I8 June 2004; accepted 2 I June 2004; published online 10 August 2004 role in malignant progression. Folkman $(1971,1995)$ postulated that tumour growth to macroscopic size only becomes possible as a result of this neovascularisation induced by secretion of angiogenic factors, as a result of which the improved tumour blood flow ensures the supply of oxygen and nutrients necessary for further cell proliferation (Harris, 2002). Thus, tissue hypoxia seems to be important for a needs-related modification of the oxygen and nutrient supply, the $\mathrm{pH}$ or the bioenergetic status, which together form the so-called metabolic tumour microenvironment. Hypoxia may therefore lead to an improvement in the oxygenation status of the tumour and thus promote subsequent tumour progression (Coleman et al, 2001). However, besides hypoxia, other mechanisms (e.g. oncogene expression) also seem to contribute to angiogenesis (Feldkamp et al, 1999; Zhang et al, 2001; Rak and Yu, 2004).

Vessels formed during hypoxia-induced angiogenesis show several structural and functional abnormalities compared to those in normal tissues. These abnormalities include blind endings of vessels, irregular branching patterns, loss of vascular hierarchy, absence of endothelial lining, increased vascular permeability and high fraction of arterio-venous shunt perfusion (Konerding et al, 1989a, b, 1999; Vaupel et al, 1989, 2001), and may result in an inadequate perfusion, which does not follow a regular pattern (Vaupel et al, 1989). These abnormalities lead to increased intervascular distances limiting the diffusive oxygen flux to the tumour cells and thus result in an insufficient cellular $\mathrm{O}_{2}$ supply. 
In addition, tumour blood flow in these newly formed vessels has been seen to undergo temporal fluctuations with intermittent flow stops in individual vessels (Chaplin and Hill, 1995; Kimura et al, 1996).

From these findings it becomes clear that although hypoxia can stimulate angiogenesis and by this may increase blood supply to the tumour, it can at the same time cause limitations in the oxygen supply due to the structural abnormalities of the newly formed vessels. For this reason, the impact of long-term hypoxia on changes in the vascular structure, perfusion or metabolic microenvironment cannot be predicted. Due to hypoxia-induced changes in the activities of glycolytic enzymes, the metabolic behaviour of the tumour may change so that chronic hypoxia may also induce fundamental changes in the microenvironment. These aspects become even more important considering that the aim of some therapeutic concepts is to increase tumour hypoxia (Wood et al, 1994) in order to improve the efficacy of anticancer drugs, which act preferentially on hypoxic cells (Coleman et al, 1984; Brown, 1993; Greco et al, 2002; Wouters et al, 2002; Henk et al, 2003). At present, it is unclear what impact long-term hypoxia has on the microenvironment of solid tumours. In particular, the question arises whether chronic tumour hypoxia (over several days) induces adaptive processes modulating the oxygen and nutrient supply to the cells.

The aim of the present study was to assess changes in oxygenation and metabolic and bioenergetic parameters as a consequence of an increase in tumour hypoxia. The $\mathrm{O}_{2}$ status of experimental tumours was therefore intentionally worsened by inspiratory hypoxia over the whole period of tumour growth (6-14 days). Subsequently, oxygenation, metabolic and bioenergetic parameters of the tumours were determined. In order to study the underlying mechanisms by which the oxygen and nutrient supply of the tissue was modified, vascularisation and perfusion were evaluated.

\section{MATERIALS AND METHODS}

\section{Animals and tumours}

Male Sprague-Dawley rats (Charles River Deutschland, Sulzfeld, Germany; body weight 190-240 g) housed in our animal care facility were used in this study. They received a standard diet and acidified water ad libitum. Experimental tumours grew following subcutaneous injection of DS-ascites tumour cells $(0.4 \mathrm{ml}$; approximately $10^{4}$ cells $\mu \mathrm{l}^{-1}$ ) into the dorsum of the hind foot, as flat, spherical segments and replaced the subcutis and corium completely. The volume was determined by measurement of the three orthogonal diameters of the tumour and using an ellipsoid approximation with the formula $V=d_{1} d_{2} d_{3} \pi / 6$. Tumour volume doubling time was calculated from growth curves during the exponential growth phase (days 4-12 after inoculation). Microenvironmental measurements were performed when tumours reached a target volume of $0.5-3.0 \mathrm{ml}$ approximately $6-14$ days after inoculation. Animals were housed either under normoxic ambient conditions (room air; $21 \% \mathrm{O}_{2}$ ) or in a hypoxic atmosphere containing $8 \% \mathrm{O}_{2}$ (chronic hypoxia) continuously for the whole period of tumour growth and during measurements (e.g. oxygenation measurements). For experiments analysing the impact of acute hypoxia, animals were housed under normoxic conditions during tumour growth but breathed the hypoxic gas mixture $(8 \%$ $\mathrm{O}_{2}$ ) for $20 \mathrm{~min}$ prior to and during the measurements. Studies had previously been approved by the regional ethics committee and were conducted according to UKCCCR guidelines (Workman et al, 1998) and the German Law for Animal Protection.

\section{Tumour oxygen tensions}

The distribution of tumour oxygen tensions (oxygen partial pressure, $\mathrm{pO}_{2}$ ) was measured polarographically using steel-shafted microelectrodes (outer diameter: $300 \mu \mathrm{m}$ ) and the $\mathrm{pO}_{2}$ histography system (Eppendorf, Hamburg, Germany; for more details of this method, see Vaupel et al, 1991). A small midline incision was made in the skin covering the lower abdomen and the $\mathrm{Ag} / \mathrm{AgCl}$ reference electrode was placed between the skin and the underlying musculature. For tumour $p \mathrm{O}_{2}$ measurement, a small incision was made in the skin overlying the tumour using a 24-gauge needle and the electrode advanced to a depth of approximately $1 \mathrm{~mm}$. The electrode was then automatically moved through the tissue in preset steps with an effective step length of $0.7 \mathrm{~mm}$. Approximately $100 \mathrm{pO}_{2}$ values were obtained from each tumour in up to eight parallel electrode tracks. The oxygenation status of each tumour was described by the mean and median $p_{2}$ as well as by the fraction of $\mathrm{pO}_{2}$ values $\leqslant 2.5$ and $\leqslant 5 \mathrm{mmHg}$. Oxygenation studies of individual tumours were generally carried out in less than $20 \mathrm{~min}$. Additionally, arterial blood gas analysis was performed immediately before and after tumour tissue $\mathrm{pO}_{2}$ measurements using a pH/blood gas analyser (type $\mathrm{ABL}$ 5, Radiometer, Copenhagen, Denmark) to ensure that values for the arterial blood gases were within the physiological range during the measurement period. Mean arterial blood pressure (MABP) was continuously monitored through connection of an arterial catheter placed in the left carotid artery to a Statham pressure transducer (type P 23 ID, Gould, Oxnard, CA, USA).

\section{Metabolite concentrations}

In order to analyse metabolic parameters, the tumour-bearing hind limbs of the anaesthetised animals were rapidly frozen in liquid nitrogen. Tumours were subsequently removed, ground to a fine powder and freeze-dried. Thereafter, glucose and lactate concentrations were assayed enzymatically using standard test kits (\#1442457 and \#256773; Boehringer-Mannheim, Mannheim, Germany), and ATP, ADP and AMP were measured by HPLC (for details of the methods, see Vaupel et al, 1994; Kelleher et al, 1995).

\section{Vascular endothelial growth factor concentration}

Vascular endothelial growth factor was determined by an ELISA kit detecting rat VEGF (kit DY564, R\&D Systems, Minneapolis, MN, USA) according to the manufacturer's instructions. In brief, tumours were excised and cut into small pieces. Approximately $0.5 \mathrm{~g}$ of tissue was suspended in $1.5 \mathrm{ml}$ RIPA buffer (phosphatebuffered saline, NP-40, $\mathrm{Na}^{+}$-deoxycholate + proteinase inhibitor cocktail), sonicated five times on ice and centrifuged. The protein content of the supernatant was determined using Bradford reagent (Sigma, Deisenhofen, Germany). For each measurement, approximately $50 \mu \mathrm{g}$ of protein was analysed. For this, 96-well microplates were coated with a mouse anti-rat VEGF antibody. The supernatant of the tissue preparation was diluted in PBS $+1 \%$ BSA $\left(1: 10 \mathrm{vv}^{-1}\right)$ and incubated in the wells for $2 \mathrm{~h}$ at room temperature. After washing, the detection antibody (goat anti-rat VEGF) was added and incubated for a further $2 \mathrm{~h}$ at room temperature. The optical density was determined on a microplate reader at a wavelength of $450 \mathrm{~nm}$. The VEGF concentration determined for each well was normalised to the protein content in the sample. In contrast to all other experiments, in the VEGF study, the animals in the group 'acute hypoxia' were exposed to the hypoxic atmosphere $\left(8 \% \mathrm{O}_{2}\right)$ for $18 \mathrm{~h}$ (not just for $20 \mathrm{~min}$ ) prior to tumour excision in order to leave sufficient time for the in vivo upregulation of VEGF expression to take place.

\section{Vascular density}

Endothelial cells were stained with a CD31 antibody. Cryosections with a thickness of $7 \mu \mathrm{m}$ were fixed for $15 \mathrm{~min}$ in acetone $\left(4^{\circ} \mathrm{C}\right)$. Sections were rinsed in PBS ( $\mathrm{pH}$ 7.4) and thereafter with $3 \% \mathrm{H}_{2} \mathrm{O}_{2}$. Sections were washed in PBS between all the following steps. The 
specimens were incubated in normal horse serum (Vector Laboratories, Burlingame, CA, USA) for $20 \mathrm{~min}$ and incubated overnight in CD31 antibody $(1: 100$, mouse anti-rat antibody MCA1334G, Serotec, Oxford, UK) at room temperature in humidified chambers. Biotinylated anti-mouse IgG (dilution $1: 200$, BA-2000, Vector Laboratories) was applied as a secondary antibody for $30 \mathrm{~min}$, followed by $\mathrm{ABC}$ complex (peroxidase standard kit, PK 4000, Vector Laboratories) for $30 \mathrm{~min}$. Immune complexes were made visible by incubation with AEC chromogene (peroxidase substrate kit, AEC SK-4200, Vector Laboratories) for $15 \mathrm{~min}$. The specimens were then counterstained with haematoxylin $(1: 2)$ for $2 \mathrm{~min}$ and rinsed in tap water. Finally, using aquatex mounting medium (Merck, Darmstadt, Germany), specimens were mounted with a coverslip.

All morphometric analyses were performed single-blinded by the same observer using a computerised digital image analysis system (Diskus 4.30, Hilgers, Königswinter, Germany) connected with a Zeiss Axiophot microscope (Zeiss, Jena, Germany). In each tumour, the areas with the highest microvessel density (hot spots) were identified. Quantification of the microvessels was performed in five hot spots in the tumour periphery and five hot spots in the tumour centre. The vessel counts were averaged separately for the tumour centre and periphery. Analysis of the fraction of viable tumour tissue was performed in the haematoxylin and eosinstained slices by marking necrotic areas and calculating the fraction of necrosis in the image.

\section{Perfusion-related parameters}

In order to assess parameters related to the perfusion distribution within a tumour, the fluorescent dye Hoechst 33342 (Sigma, Deisenhofen, Germany) was injected i.v. at a dose of $25 \mathrm{mg} \mathrm{kg}^{-1}$ body weight. For this, the dye was dissolved at a concentration of $10 \mathrm{mg} \mathrm{ml}^{-1}$ in isotonic saline and approximately $0.5 \mathrm{ml}$ of this stock solution was rapidly injected into a tail vein. At $60 \mathrm{~s}$ after injection, animals were killed by an overdose of anaesthetic and the tumours were rapidly frozen in liquid nitrogen. Following subsequent tumour removal, cryosections were prepared. Using fluorescence microscopy (filter set \#02, Zeiss, Jena, Germany, excitation wavelength: $365 \mathrm{~nm}$, emission filter: low-pass $420 \mathrm{~nm}$ ) at low resolution (range of vision $3 \times 2.5 \mathrm{~mm}$ ), images of perfused vessels were taken from two to three different regions of each cryosection. Approximately three to four sections from each tumour were analysed resulting in 9-10 images per tumour. In these images, each vessel was marked and the mean density of perfused vessels, the mean distance between neighbouring vessels and the area of vascular domains were calculated using image analysis software (Optimas Ver. 6.2, Media Cybernetics, Silver Spring, MD, USA).

\section{DNA content and proliferation analysis}

For analysis of DNA content and the fraction of actively DNAsynthesising cells, tumours were labelled with bromodeoxyuridine (BrdU). For this, BrdU (Boehringer-Mannheim, Mannheim, Germany) was dissolved in PBS at a concentration of $10 \mathrm{mg} \mathrm{ml}^{-1}$ and injected i.p. (150 $\mathrm{mg} \mathrm{kg}^{-1}$ body weight). After $120 \mathrm{~min}$, tumours were excised and dissipated into a single cell suspension. Incorporated BrdU was detected using monoclonal antibodies and DNA content was determined by propidium iodide staining (for details of the methods, see Thews et al, 1996).

\section{Blood cell parameters}

Blood cell parameters were assessed using a multiparameter, automated haematology analyser (Ac-T8; Beckman-Coulter, Krefeld, Germany), whereby erythrocyte, white blood cell and platelet counts together with the mean red blood cell (RBC) volume (MCV) were measured by impedance and the haemoglobin concentration was measured by a photometric method. In addition, the analyser uses the measured values to calculate several other parameters (e.g. haematocrit, mean corpuscular haemoglobin content $(\mathrm{MCH})$ ). All measurements were performed using a sample of venous blood $(20 \mu \mathrm{l})$ taken from a tail vein.

\section{Statistical analysis}

Results are expressed as means \pm s.e.m. unless stated otherwise. Differences between groups were assessed by the two-tailed Wilcoxon test for unpaired samples. The significance level was set at $\alpha=5 \%$ for all comparisons.

\section{RESULTS}

Exposing rats to an atmosphere containing a reduced oxygen fraction (8\%) over a prolonged period of time (6-14 days) affects several systemic parameters. As might be expected, inspiratory hypoxia markedly stimulated erythropoiesis, as indicated by a significantly higher haemoglobin concentration and haematocrit as well as an increased number of RBCs (Table 1). However, mean erythrocyte volume (MCV) and cellular haemoglobin content (MHC) remained in the normal range. In parallel, the spleen wet weight of the animals was significantly reduced under hypoxic conditions $(0.82 \pm 0.23 \mathrm{~g})$ compared to control animals $(1.06 \pm 0.24 \mathrm{~g}, P=0.032)$. Hypoxia led to a significant reduction in arterial $p \mathrm{O}_{2}$ followed by a stimulation of ventilation as indicated by a lower arterial $p \mathrm{CO}_{2}$ and a higher $\mathrm{pH}$ (Table 2). Arterial $p \mathrm{O}_{2}$ in chronically hypoxic animals was slightly higher compared to acute hypoxia ( $38 \pm 1$ vs $33 \pm 2 \mathrm{mmHg}$ ), possibly indicating an adaptation of ventilation to a chronically reduced inspiratory $\mathrm{O}_{2}$ fraction.

Housing animals under hypoxic environmental conditions also had an impact on the growth behaviour of experimental tumours. Under control conditions (breathing room air), the DS-sarcoma used in the study had a volume doubling time of 2.4 days (during the exponential growing phase), whereas tumours growing under inspiratory hypoxia had a significantly longer volume doubling time (3.0 days; Figure 1). Since the dependency of oxygenation, bioenergetic status, fraction of viable tissue and perfusion on tumour volume is well documented for many experimental tumour models, all comparisons of these parameters in this study were performed on tumours of comparable size. For this reason, parameters were measured on different days after tumour implantation when tumours reached a mean volume of approximately $1.5 \mathrm{ml}$.

Although the cell cycle distribution was not markedly different between the two groups, the fraction of actively DNA-synthesising cells as measured by BrdU incorporation was significantly lower in the group exposed to inspiratory hypoxia (Figure 2). Since the fraction of cells in the $S$ phase of the cell cycle was not different,

Table I RBC-related parameters in control animals and animals housed under chronically hypoxic conditions (inspiratory $\mathrm{O}_{2}$ fraction $=8 \%$ ) for the whole period of tumour growth (6-14 days)

\begin{tabular}{lccc}
\hline & Control & $\begin{array}{c}\text { Chronic } \\
\text { hypoxia }\end{array}$ & P-value \\
\hline$n$ & 7 & 6 & \\
$\mathrm{cHb}\left(\mathrm{gl}^{-1}\right)$ & $137 \pm 4$ & $167 \pm 3$ & 0.003 \\
Haematocrit $(\%)$ & $42 \pm 1$ & $51 \pm 1$ & 0.003 \\
RBC count $\left(10^{6} \mu \mathrm{I}^{-1}\right)$ & $7.0 \pm 0.2$ & $8.4 \pm 0.1$ & 0.005 \\
Mean corpuscular volume & $59 \pm 1$ & $61 \pm 1$ & 0.284 \\
(MCV) (fl) & & $20 \pm 1$ & 0.316 \\
Mean corpuscular haemoglobin & $20 \pm 1$ & & \\
(MCH) (pg) & & & \\
\hline
\end{tabular}

$n=$ number of tumours investigated; $\mathrm{cHb}=$ haemoglobin concentration. 
Table 2 Arterial $\mathrm{pO}_{2}, p \mathrm{CO}_{2}$ and $\mathrm{pH}$ in control animals, in animals during acute reduction of the inspiratory $\mathrm{O}_{2}$ fraction for 20 min (acute hypoxia) and during chronic inspiratory hypoxia for $6-14$ days (chronic hypoxia)

\begin{tabular}{lcccc}
\hline & $\mathbf{n}$ & $\mathbf{p O}_{\mathbf{2}} \mathbf{( \mathbf { m m H g } )}$ & $\mathbf{p C O}_{\mathbf{2}} \mathbf{( \mathbf { m m H g } )}$ & $\mathbf{p H}$ \\
\hline Control & 19 & $78 \pm 1$ & $48 \pm 1$ & $7.41 \pm 0.03$ \\
Acute hypoxia & 22 & $33 \pm 2 *$ & $32 \pm 1 *$ & $7.50 \pm 0.01 *$ \\
Chronic hypoxia & 17 & $38 \pm 1^{* * * *}$ & $29 \pm 2 *$ & $7.49 \pm 0.01 *$ \\
\hline
\end{tabular}

$n=$ number of tumours investigated. $* P<0.001$ vs control; $* * P<0.05$ vs acute hypoxia.

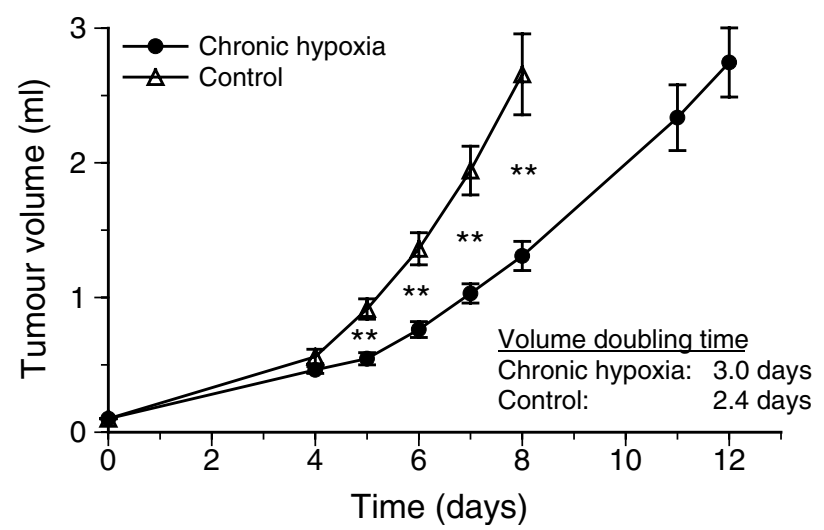

Figure I Tumour growth during chronic inspiratory hypoxia $\left(\mathrm{O}_{2}\right.$ fraction $8 \%, n=22)$ and in normoxic control tumours $(n=\mid 8)$. Values are expressed by mean \pm s.e.m.; $* * * 0.001$.

the fraction of cells not incorporating BrdU during the $S$ phase was slightly higher in chronically hypoxic cells than under control conditions. These data indicate a prolongation of the cell cycle $S$ phase during chronic hypoxia rather than an arrest of cells during proliferation.

Inspiratory hypoxia strongly affects the oxygenation status of the tumour. An acute reduction in the inspiratory $\mathrm{O}_{2}$ fraction to $8 \%$ reduces the median $p_{2}$ from $10 \mathrm{mmHg}$ (control) to $1 \mathrm{mmHg}$ within $20 \mathrm{~min}$ (Figure 3). In parallel, the fraction of hypoxic $\mathrm{pO}_{2}$ values $\leqslant 2.5 \mathrm{mmHg}$ significantly increased from 17 to $77 \%$ (Figure 3). However, during chronic hypoxia (lasting the whole period of tumour growth), the worsening of the $\mathrm{O}_{2}$ status was less pronounced: the median $\mathrm{pO}_{2}$ was $4 \mathrm{mmHg}$ and the fraction of hypoxic $\mathrm{pO}_{2}$ values $\leqslant 2.5 \mathrm{mmHg}$ was $44 \%$ (Figure 3 ).

These differences in tumour oxygenation also have an impact on the metabolic and bioenergetic status. Although the glucose concentration in the tumours was not markedly different between the three groups (control: $1.35 \pm 0.13 \mu \mathrm{molg}^{-1}$; acute hypoxia: $1.43 \pm 0.10 \mu \mathrm{molg}^{-1}$; chronic hypoxia: $1.07 \pm 0.10 \mu \mathrm{molg}^{-1}$ ), the lactate level in the group acutely exposed to inspiratory hypoxia was significantly higher compared to control animals and to chronically hypoxic tumours (Figure 4A), presumably indicating an increased level of glycolysis. In turn, the ATP concentration in the acute hypoxia tumours was significantly lower compared to those in control animals and under chronic hypoxia (Figure 4B).

Although the results of tumour oxygenation and metabolic parameters indicate that the $\mathrm{O}_{2}$ supply and thus the energy yield are reduced during inspiratory hypoxia, the tumour tissue was still found to be non-necrotic. The fraction of viable tissue was $70 \pm 3 \%$ in control tumours and $75 \pm 6 \%$ in tumours grown under chronically hypoxic conditions. Even though apoptosis was not measured directly in this study, the fraction of tumour cells with a DNA content below that of $G_{0}$ cells can be used as a measure of apoptosis. This fraction was found to be low in chronically hypoxic

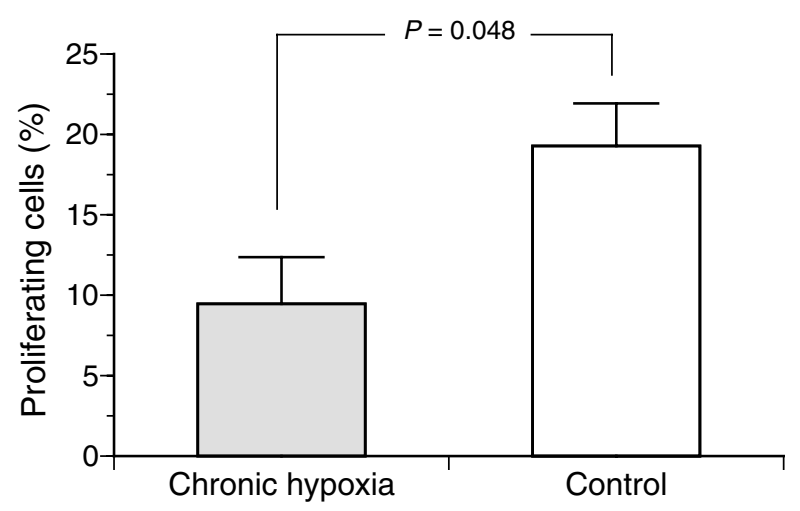

Figure 2 Fraction of actively DNA-synthesising cells as measured by BrdU incorporation during chronic inspiratory hypoxia $(n=8)$ and under control conditions $(n=\mid 8)$.
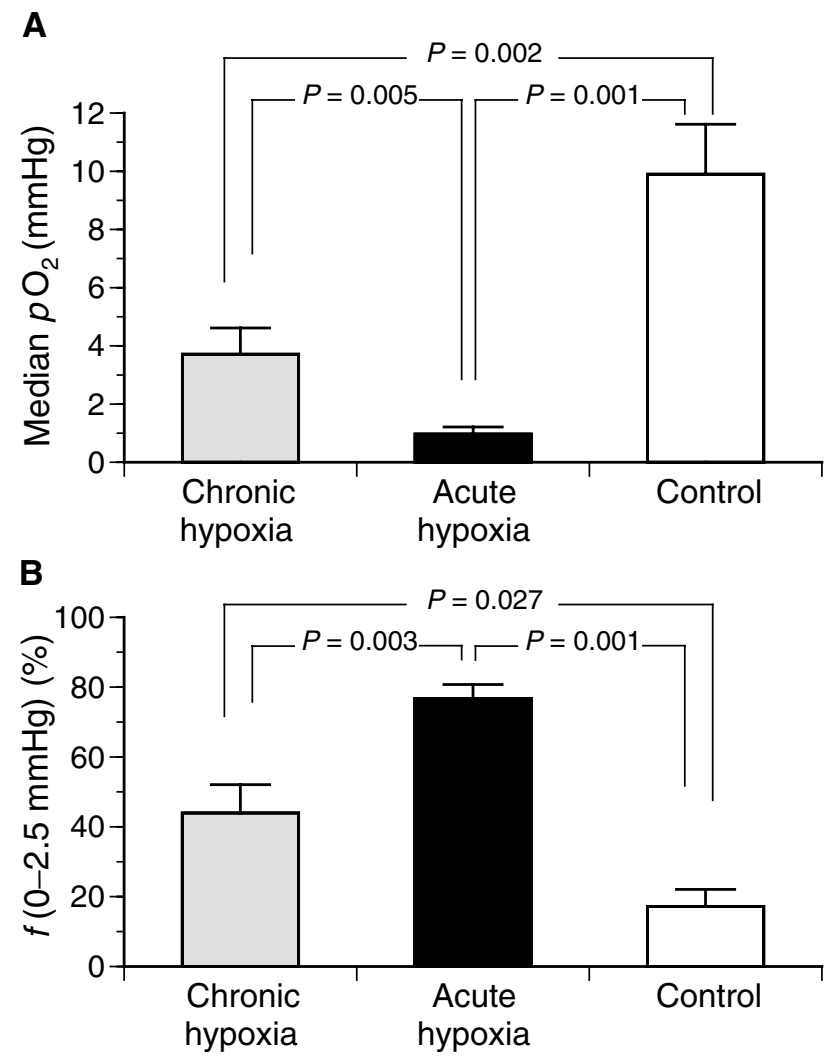

Figure 3 (A) Median tumour $\mathrm{pO}_{2}$ and (B) fraction of hypoxic $\mathrm{pO}_{2}$ values $\leqslant 2.5 \mathrm{mmHg}$ during chronic inspiratory hypoxia (chronic hypoxia, $n=17$ ), acute reduction of the inspiratory $\mathrm{O}_{2}$ fraction for $20 \mathrm{~min}$ (acute hypoxia, $n=18)$ and under normoxic control conditions $(n=2 \mid)$.

as well as in control tumours $(9 \pm 1$ and $5 \pm 1 \%$, respectively; $P=0.002$ ).

In addition, no marked differences were seen in the vascularity of tumours in both groups (Figure 5A and B). In order to analyse the impact of inspiratory hypoxia (resulting in a pronounced $\mathrm{O}_{2}$ deficiency in the tumour) on the induction of vessel formation, the vascular densities in areas of high vascular density (hot spots) in the tumour centre and periphery were determined. However, neither the size of the hot spots nor the mean or maximum vascular density within the hot spots (Table 3) was markedly different (and not statistically significant) between the groups 
A

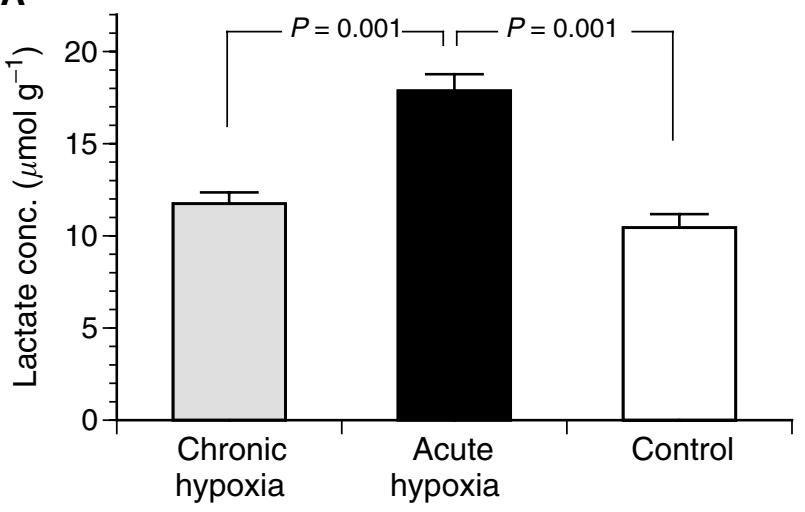

B

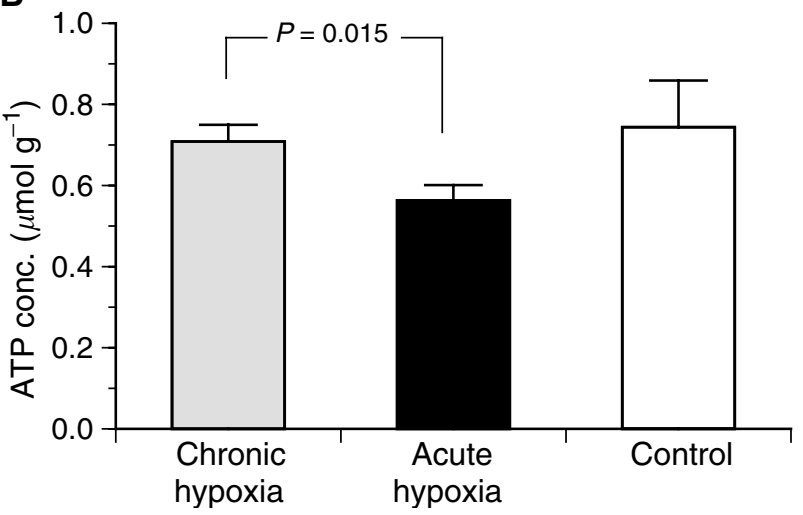

Figure 4 (A) Mean lactate and (B) ATP concentrations in tumours during chronic inspiratory hypoxia (chronic hypoxia, $n=22$ ), acute reduction of the inspiratory $\mathrm{O}_{2}$ fraction for $20 \mathrm{~min}$ (acute hypoxia, $n=30)$ and under normoxic control conditions $(n=12)$.

studied. The results of the vascularity evaluation reflect the findings of the VEGF concentration measurements. Even though the DS-sarcoma cells are able to upregulate VEGF expression under hypoxic conditions in vitro (data not shown), no marked differences in the VEGF level in tumours of the different groups were seen in the in vivo situation (Figure 6). Higher VEGF concentrations as compared to controls were not found either in tumours of animals kept under hypoxia only for $18 \mathrm{~h}$ prior to tumour excision ('acute hypoxia') or in animals housed for the whole period of tumour growth in an oxygen-reduced atmosphere ('chronic hypoxia').

Even though the number of vessels (as indicated by CD31 staining) was not different in chronically hypoxic tumours as compared to controls (Figure 5A and $\mathrm{B}$ ), the pattern of perfusion distribution varied profoundly (Figure $5 \mathrm{C}-\mathrm{E}$ ). In acutely hypoxic tumours, the density of perfused vessels was more than halved as compared to control animals (Figures 5D and 7A). In parallel, the mean distance between neighbouring perfused vessels was dramatically increased $(655 \pm 181 \mu \mathrm{m})$ to values far greater than the oxygen diffusion distance. In tumours under chronic inspiratory hypoxia conditions, the mean number of perfused vessels was also reduced to approximately the same extent as during acute hypoxia (Figure 7A). However, the spatial distribution of perfusion in these tumours was much less heterogeneous (Figure 5E). In chronically hypoxic tumours, the mean intervascular distance between perfused vessels was markedly reduced $(317 \pm 114 \mu \mathrm{m}$, although due to large interindividual variability it was not statistically significant). These data indicate a trend to a more uniform perfusion compared to acute hypoxia, although values of control tumours were not reached $(134 \pm 3 \mu \mathrm{m})$. This
A

Normoxia

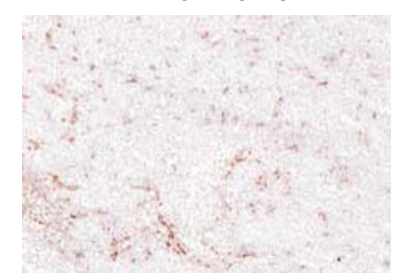

C

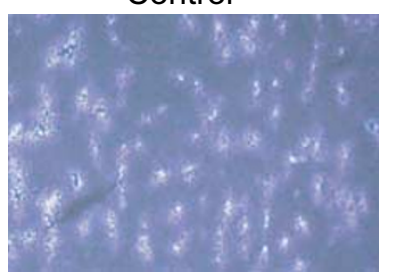

B Chronic hypoxia

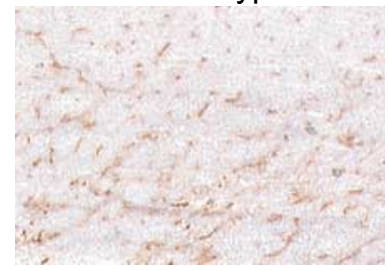

D

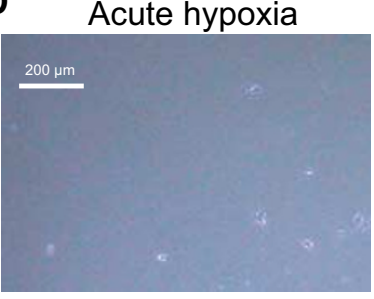

E

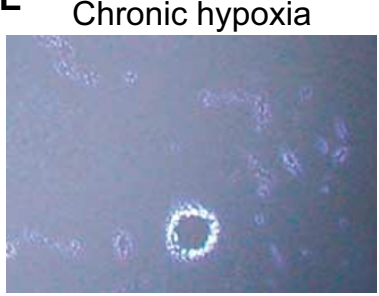

Figure 5 Examples of vascular patterns (CD3| staining) in tumours growing under either $(\mathbf{A})$ normoxic conditions or $(\mathbf{B})$ during chronic inspiratory hypoxia, and of perfusion distribution (Hoechst 33342 staining) under $(\mathbf{C})$ normoxic control conditions, during $(\mathbf{D})$ acute reduction of the inspiratory $\mathrm{O}_{2}$ fraction for 20 min or during $(\mathbf{E})$ chronic inspiratory hypoxia. All images are scaled to the same magnification.

trend also becomes obvious when the fraction of vessels that are more than $350 \mu \mathrm{m}$ away from the next perfused vessel is calculated (Figure 7B). One possible reason for the reduced perfusion seen during inspiratory hypoxia despite a constant number of tumour vessels may be a decrease in MABP during hypoxia. In control animals, MABP was $139 \pm 2 \mathrm{mmHg}$, in acute hypoxia it was reduced to $77 \pm 2 \mathrm{mmHg}$ and in animals kept chronically under hypoxia it was $88 \pm 3 \mathrm{mmHg}(P=0.0052$ vs acute hypoxia).

\section{DISCUSSION}

In the present study, the impact of pronounced chronic hypoxia on adaptive processes in tumours has been analysed. For this, experimental tumours, which show $\mathrm{O}_{2}$ deficiency even under control conditions (approximately $20 \% \quad \mathrm{pO}_{2}$ values below $2.5 \mathrm{mmHg}$ ), were artificially made even more hypoxic by exposing the animals to a hypoxic atmosphere containing $8 \%$ oxygen for the period of tumour growth. However, this procedure induces severe hypoxia systemically in the whole animal rather than just in the tumour. Therefore, several other processes that are not directly related to tumour hypoxia and that in turn may affect the tumour microenvironment might be induced. For instance, the measured blood gas parameters (Table 2) indicate that during acute as well as during chronic inspiratory hypoxia, ventilation was stimulated and a respiratory alkalosis was induced leading to a higher affinity of $\mathrm{O}_{2}$ to haemoglobin (as indicated by a left shift of oxyhaemoglobin dissociation curve). This mechanism may contribute to the worsening of the $\mathrm{O}_{2}$ supply to the tumour and by this increase tumour hypoxia. On the other hand, hypoxaemia induces 
Table 3 Area size of vascular 'hot spots', mean and maximum vascular density within the 'hot spots' in control tumours and in tumours grown under chronically hypoxic conditions in vivo (inspiratory $\mathrm{O}_{2}$ fraction $=8 \%$ )

\begin{tabular}{|c|c|c|c|c|}
\hline & \multicolumn{2}{|c|}{ Tumour centre } & \multicolumn{2}{|c|}{ Tumour periphery } \\
\hline & Control & Chronic hypoxia & Control & Chronic hypoxia \\
\hline$n$ & 6 & 10 & 6 & 10 \\
\hline Area of hot spots $\left(\mathrm{mm}^{2}\right)$ & $0.21 \pm 0.07$ & $0.22 \pm 0.04$ & $0.15 \pm 0.02$ & $0.21 \pm 0.04$ \\
\hline Mean vascular density in the hot spots (vessels $\mathrm{mm}^{-2}$ ) & $348 \pm 49$ & $258 \pm 40$ & $315 \pm 55$ & $322 \pm 63$ \\
\hline Maximum vascular density in the hot spots (vessels $\mathrm{mm}^{-2}$ ) & $529 \pm 62$ & $385 \pm 53$ & $507 \pm 101$ & $423 \pm 80$ \\
\hline
\end{tabular}

Tumour areas both in the centre and periphery were analysed. $n=$ number of tumours investigated.

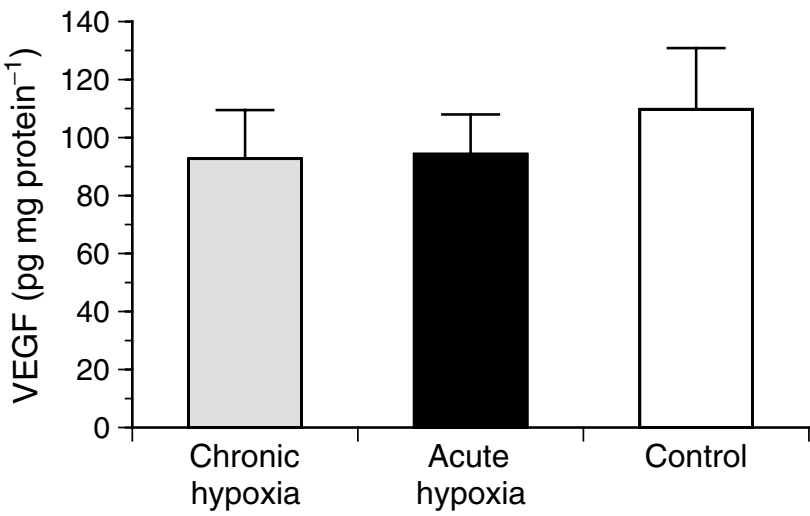

Figure 6 Vascular endothelial growth factor concentration in tumours during chronic inspiratory hypoxia (chronic hypoxia, $n=4$ ), acute reduction of the inspiratory $\mathrm{O}_{2}$ fraction for $18 \mathrm{~h}$ prior to VEGF measurements (acute hypoxia, $n=4)$ and under normoxic control conditions $(n=8)$.

erythropoietin (EPO) formation in the kidney resulting in forced erythropoiesis (as was the case in the present study; Table 1). Since several tumour cell lines express an EPO receptor (Acs et al, 2001), it has been discussed that erythropoietin may promote tumour growth (Acs et al, 2003). However, for the tumour line used in the present study (DS-sarcomas of the rat), it has been shown that EPO per se has no promoting effect on proliferation (Thews et al, 1998). On the other hand, secondary indirect effects of EPO on the tumour microenvironment (e.g. by increasing the haemoglobin level of the blood and by this improving the oxygen transport capacity; Table 1) cannot be ruled out in the present study. Therefore, the results obtained from the artificial situation of systemic hypoxia can only be transferred with caution to the situation found clinically in tumour patients.

The oxygen deficiency seen in many experimental and human tumours results from a discrepancy between oxygen demand and supply to the tissue. In particular, the convective oxygen transport with the blood is insufficient since the tumour vasculature shows chaotic vessel structure (Konerding et al, 1989a, b, 1999) resulting in a loss of coordinated blood flow (Vaupel et al, 1989; Secomb et al, 1995). In addition, temporary stasis of blood flow has been described in many experimental and human tumours (Chaplin and Hill, 1995). During systemic hypoxia, tumour blood flow becomes even worse whereby pronounced differences in the perfusion pattern of tumours were seen between acute and chronic hypoxia. During short-term hypoxia, the number of perfused vessels was dramatically decreased (Figures $5 \mathrm{D}$ and $7 \mathrm{~A}$ ), which may be the result of a hypoxia-induced reduction in arterial blood pressure (normoxia: $139 \pm 2 \mathrm{mmHg}$; acute hypoxia: $77 \pm 2 \mathrm{mmHg}$ ). Such a decrease, which has also been described by others (Marshall and Metcalfe, 1989; Sato et al, 1992; Trzebski et al, 1995) may have several reasons. Inspiratory hypoxia has been shown to induce a
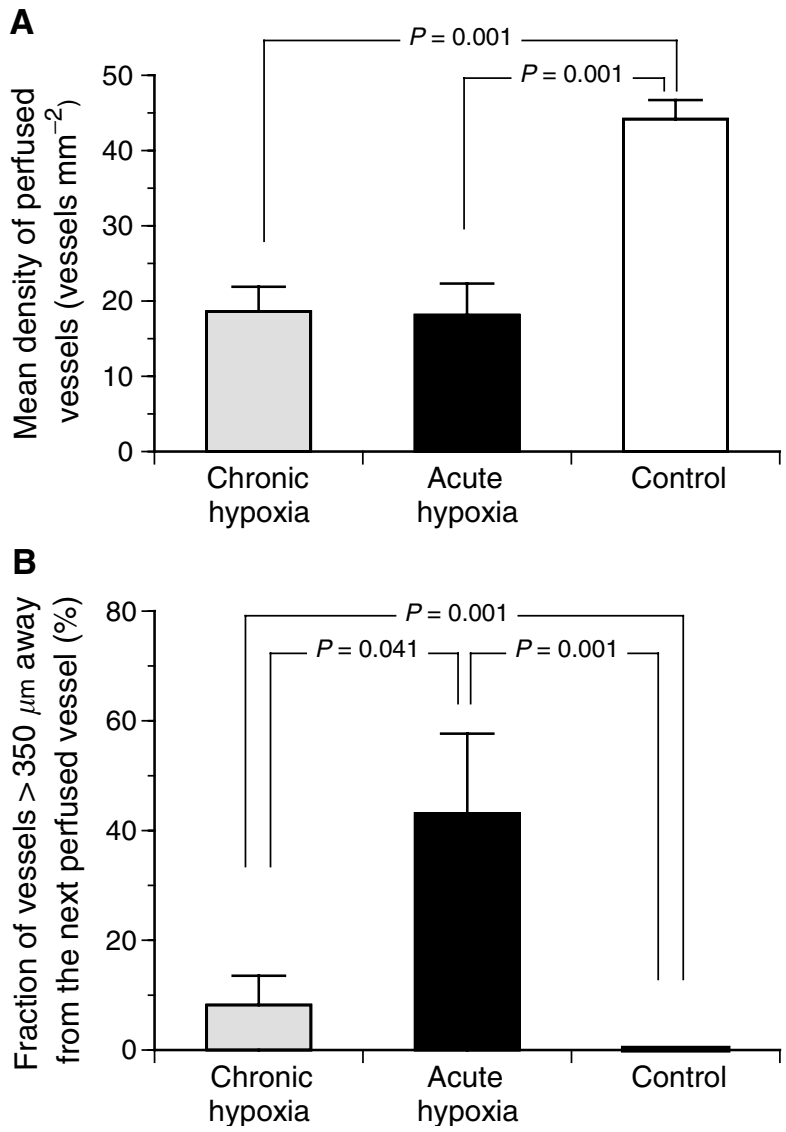

Figure 7 (A) Mean density of perfused vessels and (B) fraction of vessels more than $350 \mu \mathrm{m}$ away from the next perfused vessel (as determined by Hoechst 33342 injection) in cryosections of tumours during chronic inspiratory hypoxia (chronic hypoxia, $n=12$ ), acute reduction of the inspiratory $\mathrm{O}_{2}$ fraction for 20 min (acute hypoxia, $n=14$ ) and under normoxic control conditions $(n=10)$. In all control tumours, the distances between neighbouring perfused vessels never exceeded $350 \mu \mathrm{m}$.

more pronounced formation of NO in the lung, which may then lead to a systemic vasodilation resulting in a reduction of perfusion pressure (Hubloue et al, 2003). It has also been demonstrated that hypoxaemia can directly induce vasodilation in various organs (e.g. brain, skeletal muscle) (Marshall and Metcalfe, 1989; Harrison et al, 1990; Sato et al, 1992). However, Harrison et al (1990) showed that in skeletal muscle hypoxaemia presumably leads to an increase of perfusion of larger arteries whereas capillary blood flow was only marginally improved indicating a hypoxaemia-induced higher fraction of shunt perfusion. Such a redistribution of blood flow may also play a part in the present study in which pronounced systemic hypoxaemia is 
induced. Vasodilation in muscles of the hind limb may redistribute blood flow to the disadvantage of the tumour resulting in a reduction of perfusion disproportionate to the changes in perfusion pressure ('steal phenomenon') (Hirst, 1989). Another reason for this reduction in local perfusion could be a vasoconstriction of vessels feeding the tumour. However, since the tumours were implanted into the subcutis, this explanation seems unlikely since a hypoxic vasoconstriction has only been described in lung tissue.

Perfusion during acute inspiratory hypoxia was distributed very heterogeneously as indicated by a pronounced increase in the distance between neighbouring perfused vessels (Figures $5 \mathrm{E}$ and 7B) with a large intratumoral variability of this parameter. Tumour regions with an almost normal perfusion distribution were found closely adjacent to large areas of viable tumour tissue with almost no perfusion. During chronic hypoxia, the mean number of perfused vessels was not markedly changed as compared to acute hypoxia. However, in chronic hypoxia, perfusion was distributed much more homogeneously throughout the tissue as indicated by a significant decrease in the distance between neighbouring perfused microvessels (Figure 7B) with a smaller intraindividual variability.

One major consequence of the impaired tumour perfusion occurring during systemic hypoxia is a worsening of convective oxygen transport to the tissue. Due to the pronounced heterogeneity of tumour perfusion in acutely hypoxic tumours the median tissue $\mathrm{pO}_{2}$ is markedly reduced, whereas during chronic hypoxia the perfusion pattern becomes more homogeneous leading to an improvement of tumour oxygenation (Figure 3). However, in addition to the changes in the pattern of tumour perfusion, other reasons for a long-term adaptation to chronic hypoxia have to be considered. As described earlier (Tannock and Steel, 1970; Amellem and Pettersen, 1991), induction of chronic hypoxia reduced tumour cell proliferation as indicated by a slower tumour growth and a lower fraction of actively DNA-synthesising cells (Figures 1 and 2). This reduction in cell proliferation was not seen in anaemic animals using the same tumour model (Thews et al, 2001), presumably because anaemia resulted in an increase of tumour hypoxia, which is less pronounced (Kelleher et al, 1996) than that seen when animals were subjected to an atmosphere containing only $8 \%$ oxygen. Even though the proliferation rate was reduced in the present study, a cell cycle arrest in the $G_{1}$ phase, as has been described in cell culture experiments (Fujii et al, 2002), was not found in the in vivo situation in the present study. The fraction of cells in the $G_{0} / G_{1}$ phase in tumours under hypoxic conditions was not significantly increased as compared to controls breathing room air. For this reason, the differences in proliferation and tumour growth rate found in vivo in the present study appear to be attributable to a prolongation of the cell cycle rather than a cell cycle arrest. Another explanation may be an alteration of the $\mathrm{G}_{1} / \mathrm{S}$ checkpoint, which has been described in several tumours. However, for the tumour model used in the present study (experimental DS-sarcoma of the rat), the status of this checkpoint is not known. For this reason, it might be possible that the lack of hypoxia-induced cell cycle arrest results from a deficient $G_{1} / S$ checkpoint. Since the oxygenation status of a tissue results from a dynamic steady state between $\mathrm{O}_{2}$ delivery and consumption, the reduced number of proliferating cells may also contribute to the better oxygenation under these conditions (Thews et al, 1999). However, a previous study showed that inhibition of DNA synthesis does not necessarily result in a decrease in the $\mathrm{O}_{2}$ consumption rate of tumour cells in vivo (Thews et al, 1996).

Hirst et al (1987a, 1991) developed a model of adaptation of tumours to long-term anaemia. They described that anaemiainduced hypoxia acutely leads to a higher fraction of hypoxic cells in the tumour. When hypoxia persisted over several days, the cord of viable tumour cells around vessels was reduced, resulting in a hypoxic fraction comparable to that found in nonhypoxic controls (similar to the improvement of oxygenation in chronically compared to acutely hypoxic tumours of the present study). This model of adaptation is, however, not directly transferable to our findings described here. If a reduced $\mathrm{O}_{2}$ diffusion radius is proposed, the vascular density in these tumours should increase. In the present hypoxia model used, no differences in the morphological pattern of microvessels were found (in tumours of comparable size and with similar fractions of necrotic tissue regions). For this reason, other adaptive mechanisms have to take place in addition to the reduction of the $\mathrm{O}_{2}$ diffusion distance.

In the experimental setting used, improvement of tumour hypoxia during chronic inspiratory hypoxia may also be the result of the increased haemoglobin concentration seen (Table 1), which would lead to a higher oxygen transport capacity. Another mechanism in this context has been proposed by Hirst and Wood $(1987 \mathrm{a}, \mathrm{b})$ and involves an adaptation of tumours to long-term anaemia, again resulting in less pronounced tumour hypoxia. The authors showed that an increase in the level of 2,3-diphosphoglycerate (2,3-DPG) in erythrocytes during inspiratory hypoxia reduced the affinity of $\mathrm{O}_{2}$ to haemoglobin and by this improved the oxygen supply to the tumour cells. Even though 2,3DPG levels were not determined in the present study, this mechanism may also contribute to the long-term improvement of the $\mathrm{O}_{2}$ status to chronic hypoxia. Finally, the arterial $p \mathrm{O}_{2}$ in chronically hypoxic animals was slightly higher than during acute hypoxia (Table 2), indicating an adaptation of ventilation to chronic reduction of inspiratory $\mathrm{O}_{2}$ fraction. This higher arterial $\mathrm{pO}_{2}$ may also (at least partially) contribute to the higher tumour $\mathrm{pO}_{2}$ observed.

Another mechanism of long-term adaptation of tumour cells as well as of host tissue cells (e.g. fibroblasts in the stroma) to hypoxic conditions has to be ruled out in the present study. It has been postulated that severe hypoxia may induce the formation of new tumour blood vessels necessary for further tumour growth (Folkman, 1995). In many human tumours, a close spatial correlation of local oxygen deficiency (determined by assessment of intrinsic or extrinsic hypoxia markers, eg, HIF- $1 \alpha$ or EF5) and the production of VEGF was found (Damert et al, 1997; Maxwell et al, 1997; Blancher et al, 2000; Huss et al, 2001; Ziemer et al, 2001; Buchler et al, 2003). Pilch et al (2001) showed in an in vitro experiment that tumour cells - and even more so tumour stromaderived fibroblasts - increase their VEGF secretion rate when they are kept under hypoxia $\left(\mathrm{OO}_{2}<1.5 \mathrm{mmHg}\right.$ for $\left.24 \mathrm{~h}\right)$. Under these conditions, tumour cells were able to increase the VEGF production by up to 10 -fold compared to the basal secretion found under normoxia $\left(p \mathrm{O}_{2}=150 \mathrm{mmHg}\right)$. It should be noted, however, that these results varied between the different cell lines used. Fibroblasts were able to increase VEGF secretion by a factor of four. DS-sarcoma cells used in the present study produce small quantities of VEGF even under normoxic conditions (approximately $24 \mathrm{pgh}^{-1} 10^{-6}$ cells). When these cells were kept under hypoxia $\left(\mathrm{pO}_{2}<1.5 \mathrm{mmHg}\right.$ for $24 \mathrm{~h}$ ), VEGF secretion increased by a factor of six indicating that, in the tumour cell line used in the present study, hypoxia is able to pronouncedly induce VEGF formation in vitro. However, in vivo, the VEGF concentration in the tumour was not markedly different in animals kept under chronic hypoxia compared to normoxic conditions (Figure 6). Since the HIF- $1 \alpha$ level was not determined in the present study, it remains unclear whether hypoxia in vivo leads to HIF-1 accumulation (either directly or indirectly by increasing the NO concentration; Metzen et al, 2003) in the tumour model used. However, notable is the finding that pronounced systemic and tumour hypoxia was not able to increase VEGF concentrations markedly. As a result of these unchanged VEGF levels, parameters describing the vascular network (vascular density in tumour centre and periphery) showed no significant differences (Table 3 ).

Several explanations for the lack of VEGF induction followed by changes in the vascular structure in vivo as compared to cell culture experiments have to be taken into account. Since the 
DS-sarcomas show pronounced hypoxic regions with almost $50 \%$ of $\mathrm{pO}_{2}$ values below $2.5 \mathrm{mmHg}$ (Thews et al, 1997), it may be that VEGF production is maximally stimulated even when animals are breathing room air, such that a further increase, due to a more hypoxic environment, might not be possible. Another possible reason for the lack of an increased VEGF induction may be that the tissue hypoxia induced by a reduction of the inspiratory $\mathrm{O}_{2}$ fraction is not strong enough. Under in vitro conditions, VEGF is induced following incubation at very low $\mathrm{pO}_{2}$ values $(<1 \mathrm{mmHg})$ for several hours (Maity et al, 2001; Pilch et al, 2001). Even though the median tumour $p \mathrm{O}_{2}$ was markedly reduced in the present study by the reduction of the inspiratory $\mathrm{O}_{2}$ fraction to $8 \%$ (Figure 3 ), it is conceivable that the tissue $p \mathrm{O}_{2}$ does not reach values low enough to stimulate VEGF formation due to temporal fluctuations in the oxygenation (Chaplin et al, 1987).

Inspiratory hypoxia led to marked changes in the metabolic and bioenergetic status with a decreased glucose and ATP concentration and an increase in the lactate level (Figure 4). These findings could be the result of pronounced tumour hypoxia leading to an upregulation of enzymes of the glycolytic pathway leading to increased lactate concentration, an acidic extracellular $\mathrm{pH}$ and a reduced ATP yield seen in many tumours (Vaupel et al, 1994). However, these findings could also be the result of the observed reduction in tumour perfusion. In this case, the nutrient supply (glucose) as well as the lactate elimination from the tissue would be reduced. For this reason, the observed metabolic changes not only reflect cellular adaptation to chronic hypoxia but also mirror indirectly changes of tumour perfusion. Maybe, both mechanisms together are responsible for the observed metabolic changes.

In conclusion, pronounced long-term hypoxia in an experimental tumour induces adaptive processes resulting in an improvement of the oxygenation status (as compared to acute hypoxia). However, the increase in median $\mathrm{pO}_{2}$ does not result from a hypoxia-induced angiogenesis (e.g. by induction of VEGF) but from a functional adaptation of the perfusion pattern. Acute hypoxia results in pronounced heterogeneity of the tumour blood flow distribution, whereas chronic hypoxia leads to a more homogeneous pattern with significantly smaller distances between perfused vessels resulting in a better diffusive $\mathrm{O}_{2}$ supply to the cells. In the tumour model used, functional changes in physiological parameters appear to play a more important role in the adaptation to chronic hypoxia than hypoxia-induced alterations in VEGF expression and morphological changes of vasculature.

\section{ACKNOWLEDGEMENTS}

We thank Ms J Tillmanns for her excellent technical assistance in carrying out the animal studies. DS-sarcoma cells were provided by the German Cancer Research Centrer (DKFZ, Heidelberg).

\section{REFERENCES}

Acs G, Acs P, Beckwith SM, Pitts RL, Clements E, Wong K, Verma A (2001) Erythropoietin and erythropoietin receptor expression in human cancer. Cancer Res 61: $3561-3565$

Acs G, Zhang PJ, McGrath CM, Acs P, McBroom J, Mohyeldin A, Liu S, Lu $\mathrm{H}$, Verma A (2003) Hypoxia-inducible erythropoietin signaling in squamous dysplasia and squamous cell carcinoma of the uterine cervix and its potential role in cervical carcinogenesis and tumor progression. Am J Pathol 162: 1789-1806

Amellem O, Pettersen EO (1991) Cell inactivation and cell cycle inhibition as induced by extreme hypoxia: the possible role of cell cycle arrest as a protection against hypoxia-induced lethal damage. Cell Prolif 24: $127-141$

Blancher C, Moore JW, Talks KL, Houlbrook S, Harris AL (2000) Relationship of hypoxia-inducible factor (HIF)- $1 \alpha$ and HIF- $2 \alpha$ expression to vascular endothelial growth factor induction and hypoxia survival in human breast cancer cell lines. Cancer Res 60: 7106-7113

Brown JM (1993) SR 4233 (tirapazamine): a new anticancer drug exploiting hypoxia in solid tumors. Br J Cancer 67: 1163-1170

Buchler P, Reber HA, Buchler M, Shrinkante S, Buchler MW, Friess H, Semenza GL, Hines OJ (2003) Hypoxia-inducible factor 1 regulates vascular endothelial growth factor expression in human pancreatic cancer. Pancreas 26: 56-64

Bush RS, Jenkin RD, Allt WE, Beale FA, Bean H, Dembo AJ, Pringle JF (1978) Definitive evidence for hypoxic cells influencing cure in cancer therapy. Br J Cancer (Suppl) 37: 302-306

Chaplin DJ, Hill SA (1995) Temporal heterogeneity in microregional erythrocyte flux in experimental solid tumours. $\mathrm{Br} J$ Cancer 71: $1210-1213$

Chaplin DJ, Olive PL, Durand RE (1987) Intermittent blood flow in a murine tumor: radiobiological effects. Cancer Res 47: 597-601

Coleman CN, Mitchell JB, Camphausen K (2001) Tumor hypoxia: chicken, egg, or piece of the farm? J Clin Oncol 20: 610-615

Coleman CN, Urtasun RC, Wasserman TH, Hancock S, Harris JW, Halsey J, Hirst VK (1984) Initial report of the phase I trial of the hypoxic cell radiosensitizer SR-2508. Int J Radiat Oncol Biol Phys 10: 1749-1753

Dachs GU, Tozer GM (2000) Hypoxia modulated gene expression: angiogenesis, metastasis and therapeutic exploitation. Eur J Cancer 36: $1649-1660$

Damert A, Machein M, Breier G, Fujita MQ, Hanahan D, Risau W, Plate KH (1997) Up-regulation of vascular endothelial growth factor expression in a rat glioma is conferred by two distinct hypoxia-driven mechanisms. Cancer Res 57: 3860-3864
Feldkamp MM, Lau N, Rak J, Kerbel RS, Guha A (1999) Normoxic and hypoxic regulation of vascular endothelial growth factor (VEGF) by astrocytoma cells is mediated by Ras. Int J Cancer 81: 118-124

Folkman J (1971) Tumor angiogenesis: therapeutic implications. N Engl J Med 285: $1182-1186$

Folkman J (1995) Clinical applications of research on angiogenesis. N Engl J Med 333: $1757-1763$

Fujii T, Otsuki T, Moriya T, Sakaguchi H, Kurebayashi J, Yata K, Uno M, Kobayashi T, Kimura T, Jo Y, Kinugawa K, Furukawa Y, Morioka M, Ueki A, Tanaka H (2002) Effect of hypoxia on human seminoma cells. Int J Oncol 20: $955-962$

Gray LH, Conger AD, Ebert M, Hornsey S, Scott OCA (1953) The concentration of oxygen dissolved in tissues at the time of irradiation as a factor in radiotherapy. Br J Radiol 26: 638-648

Greco O, Tozer GM, Dachs GU (2002) Oxic and anoxic enhancement of radiation-mediated toxicity by horseradish peroxidase/indole-3-acetic acid gene therapy. Int J Radiat Biol 78: 173-181

Harris AL (2002) Hypoxia - a key regulatory factor in tumour growth. Nat Rev Cancer 2: $38-47$

Harrison DK, Kessler M, Knauf SK (1990) Regulation of capillary blood flow and oxygen supply in skeletal muscle in dogs during hypoxaemia. $J$ Physiol 420: $431-446$

Henderson BW, Fingar VH (1987) Relationship of tumor hypoxia and response to photodynamic treatment in an experimental mouse tumor. Cancer Res 47: 3110-3114

Henk JM, Bishop K, Shepherd SF (2003) Treatment of head and neck cancer with CHART and nimorazole: phase II study. Radiother Oncol 66: $65-70$

Hirst DG (1989) Tumor blood flow modification therapeutic benefit: is this approach ready for clinical application? Review. In Gray Laboratory 1989 Annual Report, : Michael B, Hance M (eds) pp 14-17, London: Cancer Research Campaign

Hirst DG, Hirst VK, Joiner B, Prise V, Shaffi KM (1991) Changes in tumour morphology with alterations of oxygen availability: further evidence for oxygen as a limiting substrate. Br J Cancer 64: 54-58

Hirst DG, Wood PJ (1987a) The adaptive response of mouse tumours to anaemia and retransfusion. Int J Radiat Biol Relat Stud Phys Chem Med 51: $597-609$

Hirst DG, Wood PJ (1987b) The influence of haemoglobin affinity for oxygen on tumour radiosensitivity. Br J Cancer 55: 487-491

Höckel M, Vaupel P (2001) Tumor hypoxia: definitions and current clinical, biological, and molecular aspects. J Natl Cancer Inst 93: 266-276 
Horsman MR (1993) Hypoxia in tumors: its relevance, identification and modification. In Medical Radiology Current Topics in Clinical Radiobiology of Tumors, Beck-Bornholdt H-P (ed) pp 99-112, Berlin, Heidelberg: Springer-Verlag

Hubloue I, Biarent D, Abdel KS, Bejjani G, Kerbaul F, Naeije R, Leeman M (2003) Endogenous endothelins and nitric oxide in hypoxic pulmonary vasoconstriction. Eur Respir J 21: 19-24

Huss WJ, Hanrahan CF, Barrios RJ, Simons JW, Greenberg NM (2001) Angiogenesis and prostate cancer: identification of a molecular progression switch. Cancer Res 61: 2736-2743

Kelleher DK, Engel T, Vaupel PW (1995) Changes in microregional perfusion, oxygenation, ATP and lactate distribution in subcutaneous rat tumours upon water-filtered IR-A hyperthermia. Int J Hyperthermia 11: $241-255$

Kelleher DK, Matthiensen U, Thews O, Vaupel P (1996) Blood flow, oxygenation, and bioenergetic status of tumors after erythropoietin treatment in normal and anemic rats. Cancer Res 56: 4728-4734

Kimura H, Braun RD, Ong ET, Hsu R, Secomb TW, Papahadjopoulos D, Hong K, Dewhirst MW (1996) Fluctuations in red cell flux in tumor microvessels can lead to transient hypoxia and reoxygenation in tumor parenchyma. Cancer Res 56: 5522-5528

Konerding MA, Malkusch W, Klapthor B, van Ackern C, Fait E, Hill SA, Parkins C, Chaplin DJ, Presta M, Denekamp J (1999) Evidence for characteristic vascular patterns in solid tumours: quantitative studies using corrosion casts. Br J Cancer 80: 724-732

Konerding MA, Steinberg F, Streffer C (1989a) The vasculature of xenotransplanted human melanomas and sarcomas on nude mice. II. Scanning and transmission electron microscopic studies. Acta Anat (Basel) 136: 27-33

Konerding MA, Steinberg F, Streffer C (1989b) The vasculature of xenotransplanted human melanomas and sarcomas on nude mice. I. Vascular corrosion casting studies. Acta Anat (Basel) 136: 21-26

Maity A, Sall W, Koch CJ, Oprysko PR, Evans SM (2001) Low $p \mathrm{O}_{2}$ and betaestradiol induce VEGF in MCF-7 and MCF-7-5C cells: relationship to in vivo hypoxia. Breast Cancer Res Treat 67: 51-60

Marshall JM, Metcalfe JD (1989) Influences on the cardiovascular response to graded levels of systemic hypoxia of the accompanying hypocapnia in the rat. J Physiol 410: $381-394$

Maxwell PH, Dachs GU, Gleadle JM, Nicholls LG, Harris AL, Stratford IJ, Hankinson O, Pugh CW, Ratcliffe PJ (1997) Hypoxia-inducible factor-1 modulates gene expression in solid tumors and influences both angiogenesis and tumor growth. Proc Natl Acad Sci USA 94: 8104-8109

Metzen E, Zhou J, Jelkmann W, Fandrey J, Brune B (2003) Nitric oxide impairs normoxic degradation of HIF- $1 \alpha$ by inhibition of prolyl hydroxylases. Mol Biol Cell 14: 3470-3481

Pilch H, Schlenger K, Steiner E, Brockerhoff P, Knapstein P, Vaupel P (2001) Hypoxia-stimulated expression of angiogenic growth factors in cervical cancer cells and cervical cancer-derived fibroblasts. Int J Gynecol Cancer 11: $137-142$

Rak J, Yu JL (2004) Oncogenes and tumor angiogenesis: the question of vascular 'supply' and vascular 'demand'. Semin Cancer Biol 14: 93 - 104

Sato A, Trzebski A, Zhou W (1992) Local cerebral blood flow responses in rats to hypercapnia and hypoxia in the rostral ventrolateral medulla and in the cortex. J Auton Nerv Syst 41: 79-86

Secomb TW, Hsu R, Ong ET, Gross JF, Dewhirst MW (1995) Analysis of the effects of oxygen supply and demand on hypoxic fraction in tumors. Acta Oncol 34: $313-316$

Semenza GL (2002) HIF-1 and tumor progression: pathophysiology and therapeutics. Trends Mol Med 8(Suppl): S62 - S67
Semenza GL (2000) Hypoxia, clonal selection, and the role of HIF-1 in tumor progression. Crit Rev Biochem Mol Biol 35: 71-103

Sutherland RM, Ausserer WA, Murphy BJ, Laderoute KR (1996) Tumor hypoxia and heterogeneity: challenges and opportunities for the future. Semin Radiat Oncol 6: 59-70

Tannock IF, Steel GG (1970) Tumor growth and cell kinetics in chronically hypoxic animals. J Natl Cancer Inst 45: 123-133

Teicher BA, Holden SA, al Achi A, Herman TS (1990) Classification of antineoplastic treatments by their differential toxicity toward putative oxygenated and hypoxic tumor subpopulations in vivo in the FSaIIC murine fibrosarcoma. Cancer Res 50: 3339-3344

Thews O, Kelleher DK, Hummel M, Vaupel P (1999) Can tumor oxygenation be improved by reducing cellular oxygen consumption? Adv Exp Med Biol 471: 525-532

Thews O, Kelleher DK, Lecher B, Vaupel P (1997) Effect of cell line and differentiation on the oxygenation status of experimental sarcomas. $A d v$ Exp Med Biol 428: 123-128

Thews O, Kelleher DK, Vaupel P (1996) In vivo oxygen consumption rate of DS sarcoma cells on inhibition of DNA synthesis. Cancer Res 56: 2009-2012

Thews O, Kelleher DK, Vaupel P (2001) Erythropoietin restores the anemiainduced reduction in cyclophosphamide cytotoxicity in rat tumors. Cancer Res 61: 1358-1361

Thews O, Koenig R, Kelleher DK, Kutzner J, Vaupel P (1998) Enhanced radiosensitivity in experimental tumours following erythropoietin treatment of chemotherapy-induced anaemia. $\mathrm{Br} J$ Cancer 78: $752-756$

Trzebski A, Sato Y, Suzuki A, Sato A (1995) Inhibition of nitric oxide synthesis potentiates the responsiveness of carotid chemoreceptors to systemic hypoxia in the rat. Neurosci Lett 190: 29-32

Vaupel P, Kallinowski F, Okunieff P (1989) Blood flow, oxygen and nutrient supply, and metabolic microenvironment of human tumors: a review. Cancer Res 49: 6449-6465

Vaupel P, Schaefer C, Okunieff P (1994) Intracellular acidosis in murine fibrosarcomas coincides with ATP depletion, hypoxia, and high levels of lactate and total $\mathrm{P}_{\mathrm{i}}$. NMR Biomed 7: 128-136

Vaupel P, Schlenger K, Knoop C, Höckel M (1991) Oxygenation of human tumors: evaluation of tissue oxygen distribution in breast cancers by computerized $\mathrm{O}_{2}$ tension measurements. Cancer Res 51: 3316-3322

Vaupel P, Thews O, Hoeckel M (2001) Treatment resistance of solid tumors - role of hypoxia and anemia. Med Oncol 18: 243-259

Wood PJ, Sansom JM, Butler SA, Stratford IJ, Cole SM, Szabo C, Thiemermann C, Adams GE (1994) Induction of hypoxia in experimental murine tumors by the nitric oxide synthase inhibitor, $N^{\mathrm{G}}$-nitro-Larginine. Cancer Res 54: 6458-6463

Workman P, Twentyman P, Balkwill F, Balmain A, Chaplin DJ, Double JA, Embleton J, Newell D, Raymond R, Stables J, Stephens T, Wallace J (1998) United Kingdom Co-ordinating Committee on Cancer Research (UKCCCR) Guidelines for the Welfare of Animals in Experimental Neoplasia (2nd edit.). Br J Cancer 77: 1-10

Wouters BG, Weppler SA, Koritzinsky M, Landuyt W, Nuyts S, Theys J, Chiu RK, Lambin P (2002) Hypoxia as a target for combined modality treatments. Eur J Cancer 38: 240-257

Zhang X, Gaspard JP, Chung DC (2001) Regulation of vascular endothelial growth factor by the Wnt and K-ras pathways in colonic neoplasia. Cancer Res 61: 6050-6054

Ziemer LS, Koch CJ, Maity A, Magarelli DP, Horan AM, Evans SM (2001) Hypoxia and VEGF mRNA expression in human tumors. Neoplasia 3: $500-508$ 